\title{
CONGENITAL TALIPES EQUINO-VARUS
}

\author{
by Joan E. Creswell, \\ Senior Orthopaedic Physiotherapist, \\ The Adelaide Children's Hospital, Adelaide, South Australia.
}

Congenital talipes equino-varus (Fig. 1) or club foot. is one of the conditions described by Hippocrates, who taught that the condition was remediable and should be treated early, with repeated manipulations, and the application of a bandage to hold the foot subsequently. Over the years many different forms of treatment for this condition have been described, each writer claiming at least partial success. Invariably, however, the results have been disappointing, with relapses occurring to varying degrees. That the problem is still far from solved is evident in the great variations in treatment seen and described throughout the world today.

\section{Historical Introduction}

In $1839 \mathrm{~W}$. J. Little described success in treating relapsed club-feet with tenotomies and careful splinting, his own club-foot having been corrected in this manner. W. Adams in 1866, claimed "complete and permanent cure" with arthrodesis of all the major joints in the foot. Following this, many different operations were devised, some on soft tissues and others on bones; many were very mutilating. and they often resulted in relapses and stiff, rigid, painful feet

Then came the swing from surgery to conservative treatment. with many writers advocating forcible manipulations under anaesthesia.

J. H. Kite, writing in the early $1930^{\circ} \mathrm{s}$, described his treatment of club-foot by a series of fixed plasters. These were done without general anaesthesia, or any forcible manipulations, as he maintained that when force was used fibrous or bony ankylosis almost always appeared in the joints of the foot.

In contrast to Kite, Denis Browne in 1937 wrote that "full correction must be obtained at the first manipulation". He maintained that this primary violent manipulation had a totally different effect from gradual manipulation, when the foot gave at the junction of the tarsus and the metatarsus and the hindfoot was left unaffected. To him, full correction occurred only when the dorsal surface of the fifth toe touched the lateral side of the leg in the extreme calcaneovalgus position. Although he had his following, Denis Browne received much criticism of his theories on the etiology and treatment of club-feet. Nevertheless. many of the splints he devised are widely used today, but often with modifications.

Kite's methods are largely followed by many people today: but recently surgery has been advocaled again. in less drastic ways than previously, and often combined with plaster correction.

Procedures practised in recent years include

(1) Elongation of the Tendo Achilles and posterior capsulotomy of the ankle joint.

(2) Transplantation of tibialis anterior to the middle or lateral border of the foot

(3) Transplantation of tibialis posterior to the dorsum of the foot.

(4) D. Evans, writing in 1961, described his success with a procedure involving soft tissue release on the medial border of the foot, re-section of the calcaneo-cuboid joint, and lengthening of the Tendo Achilles and the tibialis posterior tendon. He maintained that the essential deformity in a club-foot was the medial dislocation of the navicular on the head of the talus. and that the other elements of the deformity were secondary and adaptive.

(5) F. C. Dwyer (1963) believed that a small inverted heel prevented complete correction of a club-foot, and promoted relapse. In his procedure, he lengthened the
Tendo Achilles, osteotomized the calcaneum, and placed a wedge of bone in its medial side to correct the varus. Further, he claimed that the forefoot adduction gradually straightened out once the heel had been filly corrected.
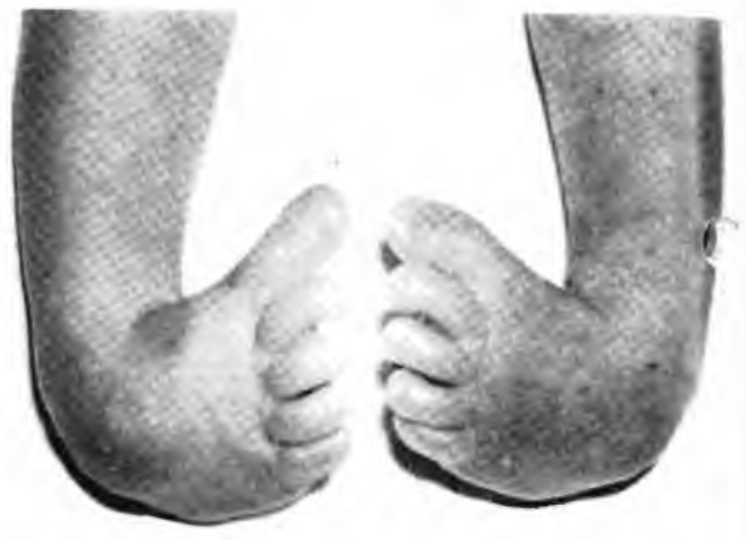

Fig. 1: Untreated congenital talipes equino-varus.

\section{Etiology}

Many theories for the cause of congenital talipes equinovarus have been advanced, but most have been largely conjecture without anatomical support, and the etiology is still uncertain

Denis Browne (1934 and 1937) put forward the hypothesis that talipes was one of a series of deformities caused by mechanical pressure in utero. He maintained that:

(1) when Congenital Talipes Equino-varus was unilateral, it was never severe.

(2) when it was bilateral it was never exactly equal, as the foot on the outer side was always worse, and

(3) there was never a severe deformity on one side and.? mild one on the other.

Various people have done dissections, but they most.y give loag descriptions of bone and joint changes, and very litule attention to the muscles.

However, A. M. Wiley (1959) reported posi-mortem dissections of six specimens, in which he found that the muscle bellies of the gastrocnemius-soleus muscles were shortened and narrowed, and the tendons were longer than normal. the total length of the calf muscles being shorter than normal. All the other muscles were approximately normal in length. Histological examination showed no definite or invariable abnormality. No constant insertional abnormalities were found. It was interesting to note that by lengthening the Tendo Achilles, he easily obtained passive correction in two cases; and, after correction, the bones of the foot lay in correct anatomical alignment.

Wynne-Davies, in 1905, provided evidence that there is often a genetic factor involved. This appears to be substantiated when the deformity occurs in several generations of a family, or in several siblings in a family.

Furthermore, Ritsila (1965) produced equino-varus deformities in experimental work with over 400 rabbits. supporting the view that soft tissue abnormalities may be il basic factor in the eliology. 


\section{Clinical Features}

Congenital talipes equino-varus is the commonest of all congenital foot deformities. It may be either unilateral or bilateral. It affects both males and females, in the ratio of approximately 2 to 1

approx deformity of a club-foot is classically taught as consisting of three main components:

(i) Adduction of the forefoot.

(2) Varus, or inversion, of the heel

(3) Equinus, or plantar fle-ion. of the ankle joint. Hence the name talipes equino-varus.

Kite (1939) elaborated further on these deformities:

(1) The calcaneun is rotated inwards under the talus, giving varus of the heel and the entire foot

(2) The equinus deformity can be divided into two parts (a) forefoot equinus, where there is plantar flexion of the forefoot in relation to the hindloot.

(b) ankle equinus, where there is plantar flexion at the ankle joint

As the deformities are fixed and are nor correctable passively, the child with an untreated or partially corrected gab-foot walks on his toes with his heel up off the ground, id the heel and foot are inverted.

During treatment, each of the three components of the deformity must be completely corrected. and in the order mentioned

\section{Associated Abnormalities}

Associated with the actual foot deformities are other abnormalities, probably in most structures below the knee.

They include

(1) Tight calf muscles

(2) Wasted calf muscles

(3) Weak peronei.

(4) "Tibial intorsion"

(5) Tibial shortening.

\section{Radiological Features}

An antero-posterior $X$-ray of an uncorrected or relapsed club-foot shows the tarsal bones are smaller and of a different shape from normal. The navicular bone articulates with the medial side of the head of the talus, instead of lying directly in front of it. The anterior end of the calcaneum is under the head of the talus instead of lying lateral to it

The lateral X-ray shows the talus is in equinus, and often the superior articular surface is flattened, instead of being rounded.

Kite maintained that

(1) When forefoot adduction is corrected the navicular is directly in front of the head of the talus, and the midline of the talus points towards the first metatarsal space.

(2) When inversion is corrected the calcaneum is rolled out from under the talus so that their anterior ends are separated, and the midline of the calcaneum points lowards the fourth and fifth toes.

\section{Principles of Treatment}

As the etiology of this condition is so uncertain, present treatment is aimed at correction of the deformity itself. There are great differences in the initial severity of it, and in the response of the individual foot to treatment. There is also a wide variation in the methods of treatment used.

Results vary greatly from place to place throughout the world, even with similar methods of treatment, one person accepting as good what another accepts as fair.

Most people agree that the initial correction of a club-foot is the easiest to obtain: and after relapse, full correction is often not obtainable.

The best foot is that which is treated by frequent gentle manipulations immediately after birth - it has been said that, in a breech birth, one should start manipulating the feet as they appear! Correction is held by either adhesive strapping, a light metal splint combined with adhesive strapping, or plaster of paris as either a removable splint or a fixed plaster. After sufficient correction has been obtained, some kind of removable splint is used for a varying length cf time.

Denis Browne described in detail his method of strapping a baby's feet onto his self-designed hobble splint. By placing adhesive felt under the outer side of the feet, and by using the leg-piece as a lever, he controlled both the varus and equinus. He then connected the two feet by a bar so that they were rotated outwards, as he maintained that correction of tibial intorsion was an important and often neglected factor, and that the normal foot pointed 20 outwards from the sagittal plane of the body. When the baby was four to five months old, the hobble splint was replaced by night boots, again joined by a bar at the bottom, and these were worn at night for at least five years. The child's morher was also shown how to stretch the foot three times daily.

Kite recommended correction by serial fixed plasters. changed weekly until the baby was three months old, and then wedged plasters. As mentioned earlier, he maintained forefoot adduction must be completely corrected first. Under-correction resulted in weight falling obliquely on the lateral side of the navicular, pushing the forefoot back into adduction, relapse thus occurring with weight bearing. Secondly, inversion must be corrected. After this, dorsifexion could be easily obtained. If the inversion was not fully corrected, the foot became rocker-bottom when dorsiflexed, breaking at the mid-tarsal joint. After full correction was obtained. Kite held the feet in fixed plasters for approximately nine weeks.

Resistant and relapsed club-feet are seen all too often, and many articles have been written in recent years about them. It is generally agreed that maximum correction should be obtained by conservative means, usually by modifications of Kite's method with fixed plasters, followed by operative procedures. There is very little mention of any after-care or retentive splinting though, and one wonders how adequately these are used

\section{Aims of Treatment}

(1) To obtain full correction of the deformity, so that the foot is good both structurally and functionally

(2) To maintain this correction indefinitely.

The deformity of a club-foot is generally considered fully corrected when the foot can be passively brought into the normal calcaneo-valgus position for that age. In the newborn, this is such that the centre of the dorsum of the foot almost touches the anterolateral aspect of the leg, and it gradually decreases with age

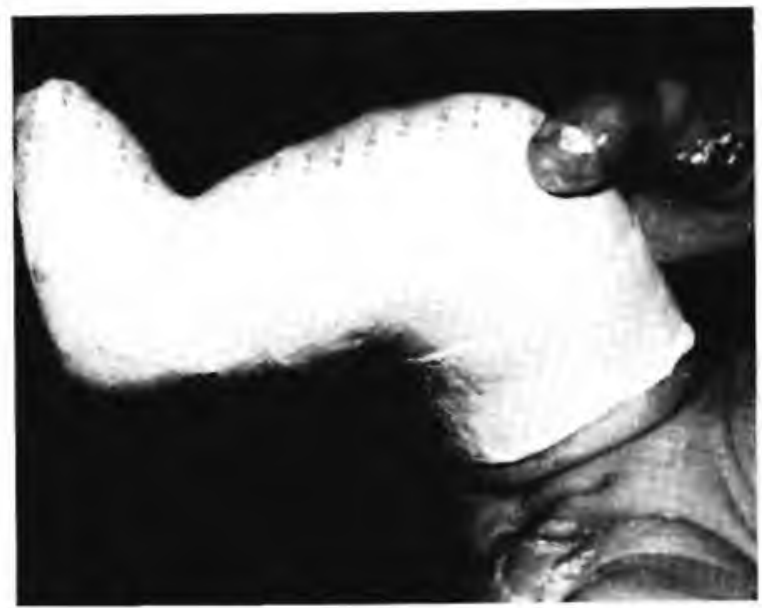

Fig. 2: Correction is held by a long leg padded fixed plaster, with the knee flexed to 90 degrees. 
Throughout growth, the club-foot will tend to relapse into its original position. This must be prevented by continuous after-care, in the form of regular manual stretching, exercises and night splintage used indefinitely, perhaps until the age of $13-14$ years when the foot is fully grown.

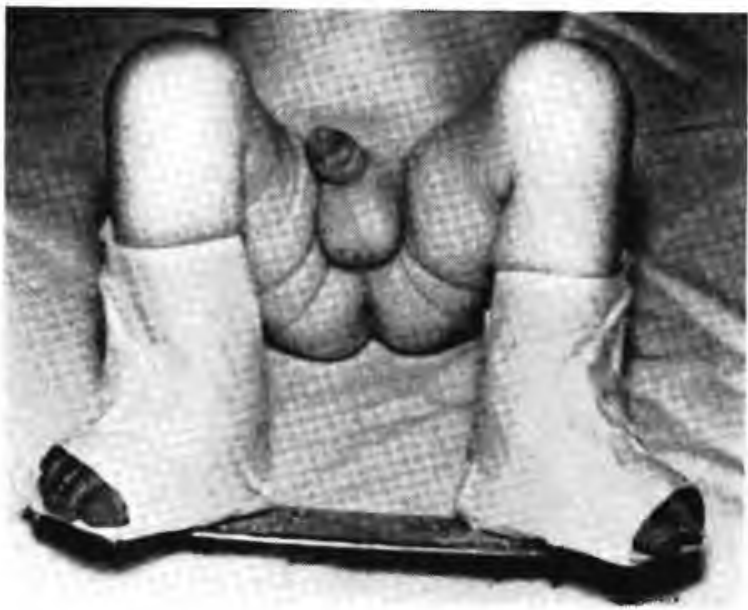

Fig. 3: Feet strapped onto a Denis Browne hobble splint.

\section{Methods of Treatment}

Our present methods of treatment at the Adelaide Children's Hospital, where we see some 30 new club-feet each year, have evolved over the last 17 years. I shall attempt to describe them here.

(I) Treatment is commenced on the day of birth if possible.

(2) The foot is manipulated very gently into the corrected position. The correction is then held by:

(a) a long-leg padded fixed plaster (Fig. 2) or

(b) a Denis Browne hobble splint and non-elastic one inch wide adhesive strapping (Fig. 3) or

(c) sometimes adhesive strapping alone, with no force used to obtain more correction. (Forceful manipulation produces a swollen foot, damages the bones and joints, and results in a very stiff foot).

(3) Gentle manipulation and splinting are repeated in 2 or 3 days at first, and this is gradually lengthened out to weekly and then fortnightly intervals in approximately 2-3 weeks. As soon as the foot corrects to the neutral position, the Denis Browne splint is used, and is reapplied every two weeks until the babe is approximately 3 months of age.

\section{Method of Strapping with the Denis Browne Splint}

A strip of adhesive felt just over one inch wide is placed down the lateral side of the lower leg, and continues under the heel to the midline. One or more small pieces of adhesive felt are also placed on the lateral hall of the sole. and of ten a piece is placed over the medial border of the forefoot. The foot is held firmly onto the footpiece of the splint, with the sidepiece free, and adhesive strapping is applied - first the forefoot is fixed to the splint, and then the heel is fixed to the postero-lateral corner of the footpiece. Next, the sidepiece is brought gently against the leg, and is strapped into position. The gaps are filled in with adhesive tape, so that the leg is firmly attached to the splint and cannot be kicked loose by the baby. Care must be taken not to apply the strapping too tightly - it is not pulled around the leg, but is just placed on the skin. The cross-bar is then added, so that the legs are in some external rotation.

If the condition is unilateral, the normal foot is strapped to the splint in the neutral position, as the affected leg cannot be kept in external rotation unless the cross-bar is attached to the normal leg.

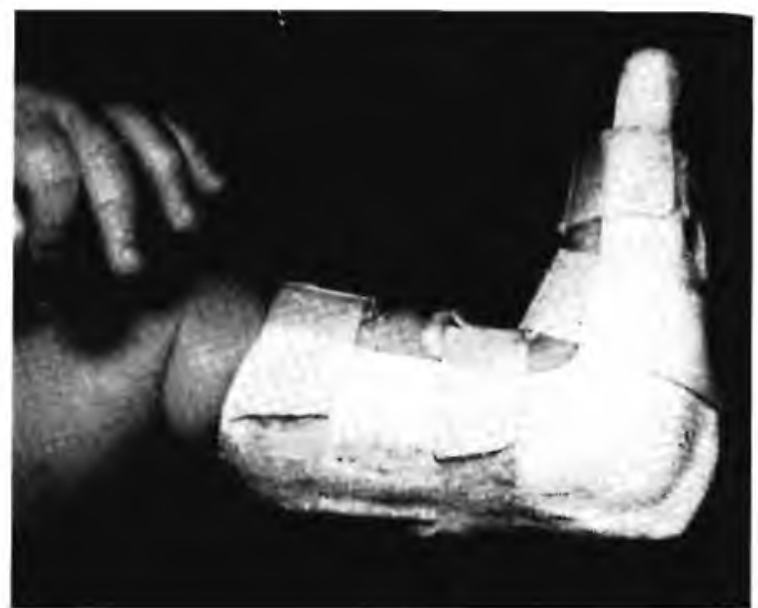

Fig. 4: Below-knee plaster back splint

(4) If the foot shows full or very good correction and is of average size at 3 months, this correction is maintaincd (not gained) by a removable below-knee plaster back splint made in the position of maximum dorsifiexion (Fig. 4). Alternatives to this and used occasionally are a Denis Browne night boot, and an above-knee plaster backsplint with the knee flexed to 90 . The splint is worn all night and for most of the day at first, but is removed for periods of approximately half an hour two or three times each day for mobilising. Gradually this free time is increased, so that by the time the babe is standing, he is using the splint only at night and for daytime sleeps. At this stage the mother is taught by the physiotherapist to stretch and exercise the foot, three times daily at first, and later only once or twice daily, to help maintain the correction. The stretches and exercises used are:

(a) passive dorsiflexion of the ankle, with pressure up in the mid-sole region, and pulling the heel down, for five minutes (Fig. 5).

(b) passive abduction of the forefoot, without forcing the heel into excessive valgus, for three minutes (Fig, 6).

(c) passive plantar flexion and dorsiflexion of the ankle joint - to increase mobility of the ankle joint, especially into plantar flexion.

(d) the mother encourages active dorsiflexion a $v$ eversion of the foot to strengthen the peronei.

Other active exercises are also used at the discretion of the physiotherapist, to increase the strength and mobility of the foot and leg.

These children usually require no special footwear or irons when they start walking, which is at the normal age. However, I prefer them in little boots at first, as they help to keep the feet plantar-grade.

(5) At any time after three months of age, if the foot is resistant to correction and is becoming boated on the medial or plantar aspects, or shows a persistent high heel with a deep transverse crease above it, surgery is performed. As our experience has increased, it has become possible to recognise these resistant feet at an early age, often at 10-12 weeks, and nowadays more than $80 \%$ of our club-feet undergo this surgery.

The Tendo Achilles is lengthened in a Z-fashion and a posterior capsulotomy of the ankle joint is done, to allow the heel to come down into the normal position. Some of oul surgeons have also done intramuscular lengthenings of tibialis posterior and the long flexors of the toes at the samc time - but I have not observed any advantage later from these. The Tendo Achilles is sutured so that it is just tight 


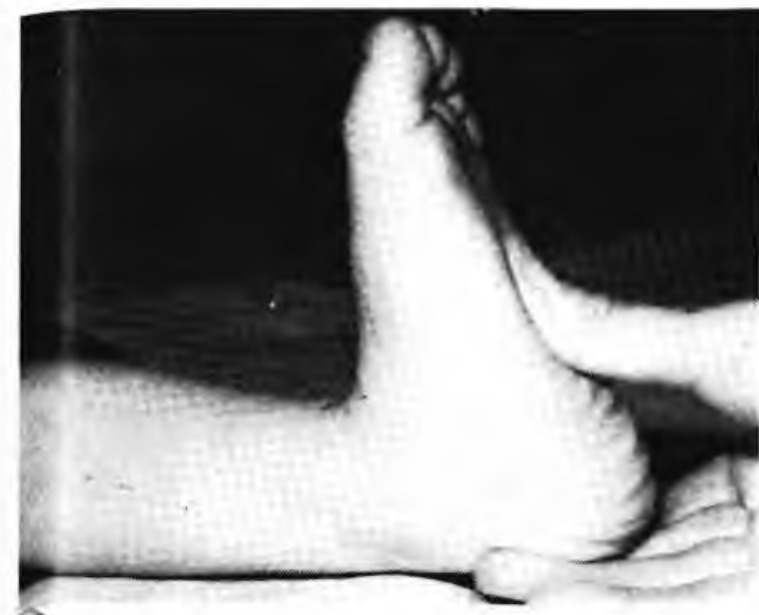

. 5: Passive stretching of the ankle joint into dorsiflexion.

with the foot at 90 dorsiflexion and the knee extended. Post-operatively, the leg is held in a long-leg padded fixed plaster for 4-6 weeks, with the ankle in maximum dorsiflexion, and the knee flexed to 90 to take the strain off the sutured Tendo Achilles. If unsufficient dorsiflexion is obtained, the plaster is changed under general anaesthesia at two weeks, when this is significantly improved.

After this, the foot requires the same treatment as the unoperated foot, with one exception, the plaster splint is only made at a right angle of dorsiflexion. This is to counteract the tendency for the foot to become fixed in the calcaneus position, when the child will walk with little or no calf action, and often with flexed knees. If it occurs, it is further improved by stretching the foot into plantar flexion also.

It is our observation that, following early elongation of the Tendo Achilles, after-care of the foot is noticeably easier, as it siretches much more easily, stays more readily in the plaster splint, and shows less tendency over the years to relapse. However, the operation is not a cure in itself, but merely part of the management of the condition, and we must make this very clear to the parents. We have seen some bad relapses where the after-care has not been continued, the same as with unoperated feet.

(6) As mentioned earlier, much stress is placed on the aftercare of the corrected foot. Night splints, stretching, and exercises are continued indefinitely at the discretion of the doctor, as most club-feet, even when fully corrected, relapse to some extent during growth. The child continues to have regular supervision by the physiotherapist, who checks the stretches done by the parents and the exercises done at home, and the night splint, which needs renewing at frequent intervals as the child grows. If the foot is holding its correction and the parents are co-operative, the child is seen only at intervals of 3-4 months.

(7) "Tibial intorsion", which is nearly always present and recurs during growth, causes the child to walk with his feet pointing somewhat medially (i.e. he intoes). It is corrected at intervals during growth by adding an adjustable external rotation bar between the night splints, so that the child sleeps with the feet and legs externally rotated. If he has a unilateral club-foot, an ordinary leather boot is worn on the good foot, and the external rotation bar is attached to this.

(8) Relapsing feet, and those commencing treatment when several months old, are first stretched in serial-wedged long fixed plasters and/or short fixed walking plasters for 6-8 weeks. We do not continue with fixed plasters for longer than this, as the feet can becone very stiffi.

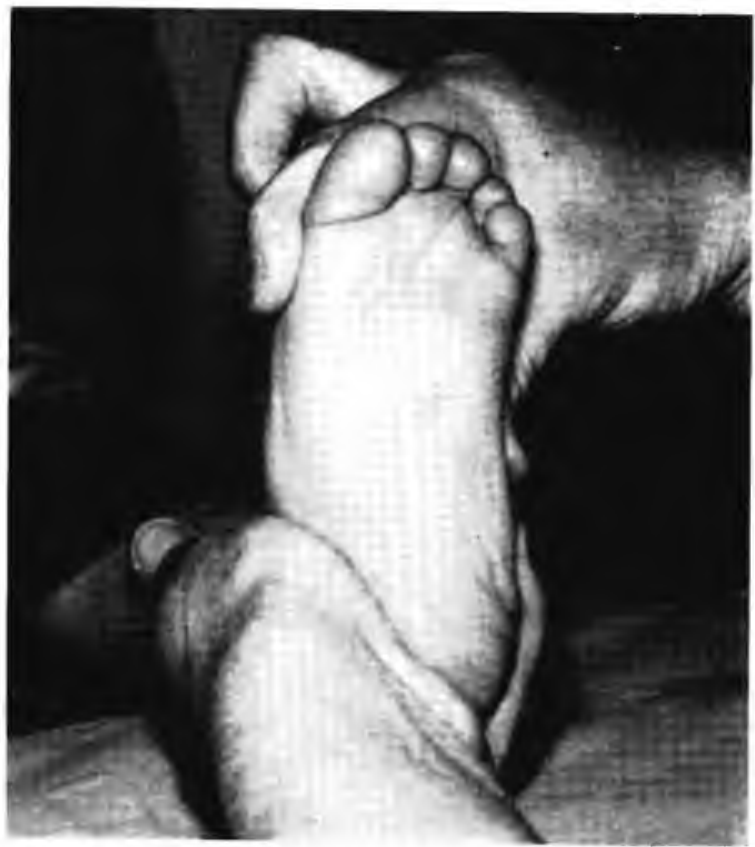

Fig. 6: Passive stretching of the forefoot into abduction

Correction is very often incomplete, and surgery is then considered necessary - frequently an elongation of the Tendo Achilles and a posterior capsulotomy of the ankle are done, and these improve things immensely. Once sufficient correction has been obtained, after-care is continued as described previously.

(9) Incompletely - corrected and badly-relapsing feet, many of which have not received adequate after-care in the home, can be improved throughout growth by various surgical procedures.

Those used most frequently are:

(a) repeat E.T.A. and posterior ankle capsulotomy.

(b) transplantation of tibialis anterior to the middle of the dorsum of the foot.

(c) transplantation of tibialis posterior to the dorsum of the foot.

(Complication - it acts as a tenodesis, and limits plantar flexion of the ankle).

With both of these tendon transplants, it is essential to stretch the foot pre-operatively in fixed plaster.

(d) osteotomies of all metatarsals - to correct forefoot adduction.

(e) osteotomy of os calcis - to correct inversion of the heel.

This can be done by two methods:

(i) insertion of a wedge of bone on the medial side, as described by Dywer (Complication often leaves an ugly scar)

(ii) Lateral displacement of distal fragment of os calcis (Disadvantage - makes the heel smaller).

(f) rotation osteotomy of the tibia - to correct persistent tibial intorsion.

Following these procedures, after-care is still necessary until growth of the foot has ceased.

(10) Definitive surgery at the end of growth is occasionally necessary for continually-relapsing feet. These are essentially bony procedures, when a wedge tarsectomy or a triple arthrodesis are performed.

(Continued on page 7) 

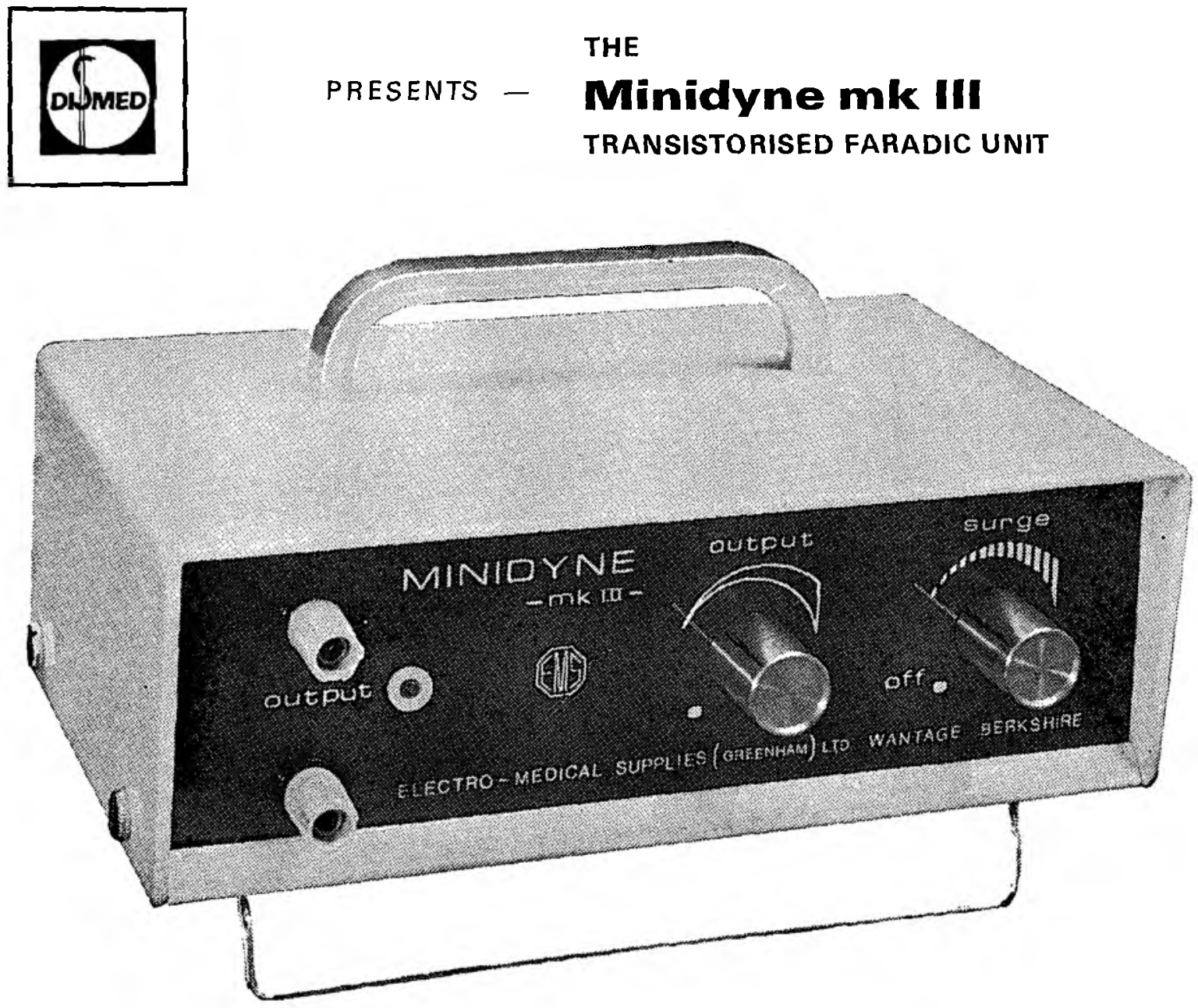

Representing another advance in the evolution of the Minidyne, the Mark III version incorporates printed circuits which reduce the size but also enhance the reliability: continuing features are

wide range of surge speed control with output sufficient for all forms of faradic techniques

audible as well as visual indication of surge speed enabling the operator to anticipate a muscle reaction without having to watch the control panel

fitted with Ever Ready PP9 batteries which will give up to six months' use without replacement and are obtainable worldwide

WEIGHT reduced to: 4 lbs. $(1,8 \mathrm{~kg})$

SIZE reduced to $8^{\prime \prime} \times 5 \frac{1}{2} " \times 2 \frac{1}{2} "(20 \mathrm{~cm} \times 13,5 \mathrm{~cm} \times 6 \mathrm{~cm})$.

PRICE:

R112,50

complete with accessories.

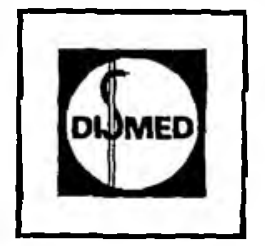

MEDICAL DISTRIBUTORS ${ }_{\mathrm{EDMS} B \mathrm{BPK}}^{\mathrm{PTY}}$

'CAPE YORK' | 252 JEPPE ST. | JOHANNESBURG | De Waal House, 172 Victoria Road | Woodstock, C.P.

PLEASE ADDRESS ALL CORRESPONDENCE TO P.O. BOX RIG ASSEBLIEF ALLE KORRESPONDENSIE AAN POSBUS

TEL. ADD. 'DISMED' PHONE | FOON 23-8106 TELEX: 43-7129 S.A.




\section{Non - Articular Rheumatism}

\author{
By W. A. McDONALD SCOTT \\ M.B., Ch.B.(Aberd), M.R.C.P.(Lond.)
}

When Shakespeare in Midsummer Night's Dream said:

"The north-east wind -

Awak'd the sleepie rheume, and so by chance

Did grace our hollow parting with a teare",

he was saying as much as was known about rheumatism three hundred and fifty years ago.

We can add little more today in spite of massive advances in the whole field of medicine, although in the "climatron" of the University of Pennsylvania, "weather" can be arranged by adjustments of temperature, humidity, air electricity and barometric pressure: in this way patients with rheumatic disease under double-blind conditions were found to have arsening of their symptoms with "a change in the weather ifht".

Non-articular rheumatism covers a wide range of aches and pains felt in the soft tissues but not associated with arthritis. The muscles and fibrous structures of the body

\section{Congenital Talipes (continued from page 5)}

\section{Conclusion}

Congenital talipes equino-varus is a serious foot dedeformity, and requires prolonged and strenuous treatment. It is often very difficult to correct adequately, and may show a vicious tendency to relapse throughout growth.

However, with early gentle manipulation and continuous splinting, soft tissue release as young as three months of age, and constant after-care until growth has ceased, a satisfactory but never normal foot can be obtained.

\section{REFERENCES}

Browne, Denis: Talipes equino-varus. Lancet II, 969, 1934. Browne, Denis: Modern Methods of Treatment of the Club foot. British Medical Journal, 2, 570, 1937.

Browne, Denis: Splinting for Controlled Movement. Reprinted from Clinical Orthopaedics, No. 8, 1956.

Dwyer, F. C.: Treatment of Relapsed Club Foot by the Insertion of a wedge into the Calcaneum. Journal of Bone \& Joint Surgery, 45B, 67, 1963.

( Ins, D.: Relapsed Club Foot. Journal of Bone \& Joint sưfgery, 43B, 722, 1961.

Fripp, A. T.: Problem of Relapsed Club Foot. Journal of Bone \& Joint Surgery, 43B, 626, 1961.

Kite, J. H.: Treatment of Congenital Club Feet. Journal of American Medical Association, 99-2, I156, 1932.

Kite, J. H.: Principles Involved in the Treatment of Congenital Club foot. Journal of Bone \& Joint Surgery, 21, 595,1939

Kite, J. H. : Treatment of Congenital Club feet. Offprint from American Academy of Orthopaedic Surgeons. Instructional Course Lectures, Vol. V 1948.

Kuhlmann, R. F., \& Bell, J. F.: Clinical Evaluation of Operative Procedures for Congenital Talipes Equino-varus. Journal of Bone \& Joint Surgery, 39A, 265, 1957.

Singer, M.: Tibialis posterior transfer in Congenital Club Foot. Journal of Bone \& Joint Surgery, 43B, 717, 1961. Singer, M., \& Fripp, A. T.: Tibialis anterior transfer in Congenital Club foot. Journal of Bone \& Joint Surgery, 40B, 252, 1958.

Southwood, R. T.: South Australian Clinics, No. 4 Vol. 5, 1971

Wiley, A. M.: An Anatomical \& Experimental Study of Muscle Growth. Journal of Bone \& Joint Surgery, 41B, 821,1959 may be affected by postural strain, by excessive use, by psychological or climatic stress and by physical injury. This leads to pain, tenderness and stiffness with associated muscle spasm in many. The precise pathology of these conditions remains obscure.

Fibrositis or muscular rheumatism is probably the commonest of all forms. It is called psychogenic rheumatism in America, suggesting that psychological stress is always a cause, which is difficult to prove. If we consider rheumatism as an expression of the result of stress on a particular temperament - the "rheumaticy" type - those whose musculoskeletal system represents a target organ in that individual then there must be a psychological component, at least.

In such a person there is of ten a history from childhood, starting with "growing pains" and continuing through adolescence and adult life with episodes of rheumatic nature.

The diagnosing of non-articular rheumatism must be tempered with caution, but in the face of obvious good general health, a normal blood sedimentation rate, a normal or raised serum uric acid and negative Latex screening test for rheumatoid arthritis, it is reasonable to make it.

Although there are several reasonably clear-cut syndromes, soft-tissue rheumatism is more easily reviewed region by region.

\section{NECK}

The diffuse aching pain of rheumatism is difficult to localise and this has been checked experimentally with hypertonic saline.

Each spinal segment has a characteristic referral area. An injection into the neck at $\mathrm{C}_{2}$ will produce aching in the back of the neck and head radiating often to the forehead. At $\mathrm{C}_{4}$, pain is felt in the side of the neck. At $C_{5}$, pain is felt in the side of the neck and the point of the shoulder. At $\mathrm{C}_{6}$, pain tends to spread down the outer side of the arm. At $\mathrm{C}_{7}$ and $\mathrm{T}_{1}$, pain spreads down the inner side of the arm. In all these areas, the skin and superficial muscles are tender to touch and spots normally sensitive to pressure become especially so. This is the common picture of fibrositis of neck and shoulders - the word that incorrectly suggests an inflammatory state.

The "nodules" are muscle bundles which can be felt, and their dispersal suggests the relief of spasm of these bundles.

\section{LOW BACK PAIN (Lumbago, Sciatica, "Slipped Disc')}

Acute episodes against a background of a "bad back" are perhaps the commonest of all the problems of nonarticular rheumatism. Although the great majority are for practical purposes musculo-skeletal the possibility of underlying pathology must be remembered. Physical, laboratory and radiological investigations should be kept to a minimum and response to therapy used as confirmation of diagnosis.

It is rare to find the absence of psychological factors, the most important being a loss of confidence in the back which helps to perpetuate symptoms. A mythology has grown up about the "slipped disc" and the inevitability of trouble if there is radiological evidence of degenerate discs. It seems that the reduction in size of the shock absorber between two vertebral bodies is considered critical in the production of pain and yet the most modern treatment of discolysis produces chemical destruction of the disc with relief of pain. Unless there is mechanical pressure on nerve roots or spinal cord by displacement of the disc, the reduction of size is unimportant.

Treatment of the patient as a personality combined with treatment of trigger points in the back will often produce regression of symptoms and gradual rehabilitation.

In general, the support of a corset or similar appliance without positive forms of therapy can be ineffectual and extremely uncomfortable in a hot climate.

\section{UPPER LIMB}

The painful shoulder, a common feature of rheumatoid arthritis, is even more common as an expression of non- 